\title{
Missing the boat: odds for the patients who leave ED without being seen
}

\author{
Jabeen Fayyaz ${ }^{*}$, Munawar Khursheed, Mohammed Umer Mir and Amber Mehmood
}

\begin{abstract}
Background: A patient left without being seen is a well-recognized indicator of Emergency Department overcrowding. The aim of this study was to define the characteristics of LWBS patients, their rates and associated factors from a tertiary care hospital of Pakistan.

Methods: A retrospective patient record review was undertaken. All patients presenting to the Aga Khan University Hospital, Karachi, between April and December of the year 2010, were included in the study. Information was collected on age, sex, presenting complaints, ED capacity, month, time, shift, day of the week, and waiting times in the ED. A basic descriptive analysis was made and the rates of LWBS patients were determined among the patient subgroups. Logistic regression analysis was used to assess the risk factors associated with a patient not being seen in the ED.
\end{abstract}

Results: A total of 38,762 patients visited ED during the study period. Among them 5,086 (13\%) patients left without being seen. Percentage of leaving was highest in the night shift (20\%). The percentage was twice as high when the ED was on diversion (19.8\%) compared to regular periods of operation (9.8\%). Mean waiting time before leaving the ED in pediatric patients was 154 minutes while for adults it was 171 minutes. More than 32\% of patients had waited for more than 180 minutes before they left without being seen, compared to the patients who were seen in ED. Important predictors for LWBS included; Triage category P4 i.e. walk -in-patients had an OR of 13.62 (8.72-21.3), Diversion status, OR 1.49(1.26-1.76), night shift, OR 2.44(1.95-3.05) and Pediatric age, OR 0.57(0.48-0.66).

Conclusions: Our study elucidates the LWBS population characteristics and identifies the risk factors for this phenomenon. Targeted interventions should be planned and implemented to decrease the waiting time and alternate services should be provided for high-risk patients (for LWBS) to minimize their number.

\section{Background}

Emergency Departments (ED) not only provide care to patients with critical and life threatening emergencies, but also look after round the clock to those who have acute yet stable medical illnesses [1-3]. The resultant ED overcrowding which was first described twenty years ago, has now become a well-established barrier in access to health care [4-6]. The problem is exacerbated in low income countries by utilization of ED as a primary access point to the healthcare especially on weekends and after hours for less urgent conditions [1]. However, the balance is now tilting towards high acuity patients, ED boarding of admitted patients, and hospital occupancy as a cause of ED overcrowding rather than influx

* Correspondence: jabeen.fayyaz@aku.edu

Department of Emergency Medicine, Aga Khan University Hospital, Karachi, Pakistan

\section{Biomed Central}

of non-urgent patients [4,5,7]. ED overcrowding not only reduces patient satisfaction but it also increases the number of patients that leave without being seen by a physician (LWBS) [3,7]. Large number of these patients may not find appropriate care elsewhere and therefore a critical treatment opportunity is missed by the health system. The percentage of LWBS patients has been recognized as a proxy indicator of ED performance and overcrowding $[8,9]$.

A number of studies from high income countries with well-established primary health care system have reported a variable number of LWBS which ranges between $<1 \%$ to $20 \%$ of all ED visits [10-14]. It has been suggested that patients who LWBS are at an increased risk of morbidity and mortality; however, a more recent administrative follow-up demonstrated these patients are at a lower risk of hospitalization and death than triage-matched controls 
[15-19]. Several factors have been found as being associated with LWBS, such as low acuity illness, young age, and male sex and prolonged waiting time [20-24]. Additionally, the triage time, previous ED visits, seasonal variation, access to primary care, diversion status and ED overcrowding also have significant impact on LWBS [10,25-29]. A literature review of local published research from Pakistan showed no study documenting the characteristics of patients who leave ED without being seen by a physician in this region.

Emergency Medicine as a specialty is still in its infancy in Pakistan [30-32]. Our department was the first one to be established back in 2008. Over the years, we have observed an increase in patient volume as well as acuity. The ED had expanded to 46 beds but the hospital beds remained the same which brought in the issues of overcrowding, left without being seen patients and ED through put issues. Therefore, this study is aimed at defining the LWBS population in a tertiary care hospital while determining percentages and factors associated with LWBS as we do not know the characteristics of our patients who are leaving. This baseline information will be critical in developing evidence based interventions aimed at improving the health care management of such patients and consequently reducing the morbidity and mortality resulting from leaving.

\section{Methods}

\section{Setting}

This study was conducted at the Emergency Department of the Aga Khan University Hospital (AKUH) Karachi, Pakistan. AKUH is a 600-bedded, private tertiary care hospital in Karachi with an annual ED census of approximately 50,000 patients and an admission rate of $37 \%$. The emergency department of AKUH is the first one established in the country, and the largest ED in Pakistan providing emergency care of international standards.

The emergency department of AKUH is the first established department at Pakistan. It has 46 patient-care beds with well designated pediatric, critical care areas and noncritical areas. An eight-bedded observation unit is also functioning where patients are kept for 24 hours. Two Fast track clinics for walk in patients provide service 24/7. AKUH-ED is the only department in Pakistan where standard triage is being followed (Additional file 1). It has a separate well defined triage area. It follows 4 levels of triage and categorizes patients from level I-level IV. We also have a written triage policy approved by the hospital. Triage staff has been given training for Triaging. A nurse initially triages patients by following the triage categories. The nurse assigns beds to the patients or sends them to the waiting area in case the ED capacity is exhausted (Additional file 2). At the triage desk, a triage team is present $24 / 7$ comprising of a trained nurse, nursing assistant and a triage care coordinator. Triage care coordinator is a senior experienced nurse who supervises the whole functioning of triage. In case of any quarry, the triage nurse could seek help from an on-call physician.

The triage information is recorded in an electronic computerized based system called ERMS (Emergency Room Management system) (Additional file 3). It is software that was developed by the information technology department of Aga Khan University Hospital (AKUH). It has two components, Triage assessment and waiting list.

Every staff working in ED has been given a login ID and password for logging in. After logging, in the windows shows two options: triage assessment and waiting patient work list. For triage assessment, the triage staff would click on the "TRIAGE ASSESSMENT" icon which opens up a new window asking for the patient details like medical record number, vitals, presenting complaints etc. After entry, this information is saved in the computer and can be retrieved later for analysis. This software also helps the staff in identifying abnormal vital signs like heart rate, blood pressure and oxygen saturation according to the age of the patients by blinking vitals in red. This way, it assists the staff in triaging the patients correctly. This study had been approved by the Ethical Review Committee (ERC) of Aga Khan University.

After filling all these information, the patient triage category triage assessment number and the bed is assigned if available. In case of non-availability of bed and the patient is not life threatening or critical, then the patient is transferred to the waiting area and this information can be reviewed by the staff later on by clicking "waiting patient list". In this way the staff completes the triage process for patients.

ED staff can review bed statistics any time by using the same software. When a bed becomes available in the ED or the defined waiting time is completed, the patient is called again for reassessment or allocation of bed. At this point they are asked to go to the registration desk and were registered with their medical record number for patients who had visited the AKUH previously as well. If that patient is visiting for the first time than a new medical record number is allocated.

When patient is assigned a bed in the ED, after waiting than this time is measured as waiting time before getting a bed. When a bed is made available than the name of the patient is called for three times by triage staff at 2 minutes interval and if a patient does not reply, they are labeled as "left without being seen" and that time is noted as their waiting time.

Return visits are recorded if the patient after leaving the emergency department comes back within 48 hours of visit. The return visits are usually tracked down through the medical record number. 


\section{Data collection}

All patients who were triaged in the Emergency Department of AKUH from April 1, 2010 to December 31, 2010, are included in the study. This time period was chosen to ensure consistency of results as we implemented a defined triage policy so to exclude any bias time period from Jan -March. We used an electronic ED record system to extract clinical data of all patients who were triaged in the AKUH-ED. Information on age, sex, complaints, and triage category, time of arrival, day of arrival, time and shift of the day when patient left the ED was recorded. Information was available on 38,762 patients for inclusion.

Four-level triage scale (P1 to P4) is used in the AKUH ED and was used for the purpose of this study. Patients with life threatening conditions are labeled P1, those in a critical state are labeled P2, P3 are patients who require urgent medical care, and $\mathrm{P} 4$ are walk-in stable patients. When all the ED beds are occupied, non-critical patients are usually asked to wait till a bed is available for them.

In this study, diversion means a situation in which the ED continues to accept critical patients despite of full occupancy but less critical patients are diverted to other healthcare facilities. This diversion status is reviewed every four hours.

\section{Statistical analysis}

Data of patients, who were treated in ED and those with LWBS visit, was compiled and analyzed. Proportions were calculated for both groups and significant differences were assessed using the Chi-square test. Percentages of LWBS visits along with their 95\% CIs were then calculated for all categories.

We used logistic regression to assess association of patient characteristics with LWBS visits at the univariate and multivariable level. For the logistic regression, LWBS visit status was taken as the outcome and its relationships with independent variables including sex of patient, age, and triage level, diversion status of ED, month and day and time of presentation. Waiting times in the ED before leaving were not included in the model due to uncertainty in their accuracy (exact value was difficult to ascertain as LWBS status was only identified when the staff called for the patient. The patient could have left any time after the initial triage). All variables were included at the univariate level and a p-value of 0.25 was considered the cut-off for inclusion in the multivariable model. The enter method was used to derive the final regression model. Unadjusted and adjusted odds ratios (ORs) are presented in the results. SPSS version 19 was used to analyze the data. An exemption of ethical approval was given by the Ethical Review Committee on 13th May, 2011 at Aga Khan University.

\section{Results}

A total of 38,762 patients were triaged from April to December 2010 at AKU - ED and were included in our study; $13866(35.33 \%)$ were admitted. Total 5,086 patients left the ED without getting medical care during this period, giving an overall rate of over $13 \%$ over 9 month period.

There were significant differences between those patients receiving medical care and those who left before treatment (Table 1). Percentage of LWBS visits for females was slightly higher than males but the relationship between sex of patient and LWBS visits was not significant in the multivariable regression model (Tables $2 \& 3$ ). For triage level assignments, proportion of patients in P3 categories was highest (15.7\%) who left without being seen, which means that they were seven times more likely to be in a LWBS visit compared to P1 \& P2 patients. The length of stay and the percentage of patients leaving were also increased with increased number of P1 and P2 patients (Figure 1). LWBS percentages seem to vary with time of the day and were more than $20 \%$ in the night shift (11 pm to $7 \mathrm{am}$ ) compared to about $4 \%$ in the morning shift (7am to 3pm). This finding was found to persist in the regression analysis, which revealed a 2.6 times higher odds of an LWBS visit if the patient presented to the ED in the night shift compared to the morning hours. Another important predictor of LWBS visit is the diversion status of the ED at the time of presentation. Patients visiting during the ED diversion hours are 1.5 times more likely to have a LWBS visit than when diversion status is off (19.8\% vs. $9.8 \%$ during off-diversion). Sex and day of the week on which the patient presented showed an association with LWBS visits at the univariate level, but this relationship was not found after adjustment with other factors in the multivariable model (Tables $2 \& 3$ ). Percentage of LWBS is more in female (13.75) patients as compared to male (12.58).

We also observed a difference in percentage of LWBS over the total study duration, being lowest in April (6.4\%) and highest in the September to October period (up to 19\%) (Table 2). This pattern was consistent in the regression model which showed higher odds of LWBS visits in October (marginally significant), November and December (Table 3).

Median waiting time for pediatric patients was 154 minutes and 171 minutes for adults who left. Patients with a waiting time of over 180 minutes had 26 times higher odds of leaving compared to those who waited for less than 30 minutes. This relationship is consistent in the adjusted multivariable model (Table 3). Relationship of wait time with age, triage category diversion status and shift of the day had been shown in Figure 2.

The top seven presenting complaints of patients with LWBS visits are shown in Figure 3. Most of the cases 
Table 1 Basic demographic characteristics of patients

\begin{tabular}{|c|c|c|c|}
\hline & 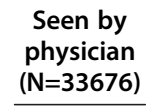 & $\begin{array}{l}\text { Left without } \\
\text { being seen } \\
(\mathrm{N}=5086) \\
\end{array}$ & P-value \\
\hline & $n(\%)$ & n (\%) & \\
\hline \multicolumn{4}{|l|}{ Sex } \\
\hline Male & $18232(54.1)$ & 2634 (51.8) & 0.031 \\
\hline Female & $15444(45.9)$ & $2452(48.2)$ & \\
\hline \multicolumn{4}{|l|}{ Age } \\
\hline$<14$ yrs & 9816 (29.1) & 933 (18.3) & $<0.001$ \\
\hline $14-20 y r s$ & $1824(5.4)$ & $311(6.1)$ & \\
\hline 20-40yrs & $8812(26.2)$ & 1791 (35.2) & \\
\hline 40-60yrs & 7091 (21.1) & 1205 (23.7) & \\
\hline 60-80yrs & 5319 (15.8) & $722(14.2)$ & \\
\hline $80 y r s$ and above & $814(2.4)$ & $125(2.5)$ & \\
\hline \multicolumn{4}{|l|}{ Triage } \\
\hline$P 1 \& P 2$ & $6850(20.3)$ & $90(1.8)$ & $<0.001$ \\
\hline P3 & 23564(70.0) & 4409(86.7) & \\
\hline P4 & $3262(9.7)$ & $587(11.5)$ & \\
\hline \multicolumn{4}{|l|}{ Diversion Status } \\
\hline Off Diversion & 23441 (69.6) & $2558(50.3)$ & $<0.001$ \\
\hline On Diversion & $10235(30.4)$ & $2528(49.7)$ & \\
\hline \multicolumn{4}{|l|}{ Months } \\
\hline April & $3356(10.0)$ & $231(4.5)$ & $<0.001$ \\
\hline May & 3656 (10.9) & 319 (6.3) & \\
\hline June & 3489 (10.4) & $320(6.3)$ & \\
\hline July & $3720(11.0)$ & $370(7.3)$ & \\
\hline August & $3707(11.0)$ & $483(9.5)$ & \\
\hline September & 4085 (12.1) & $916(18.0)$ & \\
\hline October & $4253(12.6)$ & 996 (19.6) & \\
\hline November & 3918 (11.6) & 786 (15.5) & \\
\hline December & $3492(10.4)$ & $665(13.1)$ & \\
\hline \multicolumn{4}{|l|}{ Weekdays } \\
\hline Saturday & 5057 (15.0) & 644 (12.7) & $<0.001$ \\
\hline Sunday & $5203(15.4)$ & 955 (18.8) & \\
\hline Monday & $4768(14.2)$ & $753(14.8)$ & \\
\hline Tuesday & 4655 (13.8) & 693 (13.6) & \\
\hline Wednesday & 4584 (13.6) & $661(13.0)$ & \\
\hline Thursday & 4588 (13.6) & $711(14.0)$ & \\
\hline Friday & $4821(14.3)$ & 669 (13.2) & \\
\hline \multicolumn{4}{|c|}{ Waiting time (min) } \\
\hline $0-30$ & $24035(71.4)$ & $502(9.9)$ & $<0.001$ \\
\hline $31-60$ & $2485(7.4)$ & $597(11.7)$ & \\
\hline $61-120$ & $2832(8.4)$ & $1327(26.1)$ & \\
\hline $121-180$ & $1502(4.5)$ & $998(19.6)$ & \\
\hline$>180$ & $2822(8.4)$ & $1662(32.7)$ & \\
\hline \multicolumn{4}{|l|}{ Shift } \\
\hline $7 a m-3 p m$ & $11442(34.0)$ & $514(10.1)$ & $<0.001$ \\
\hline $3 p m-11 p m$ & $12727(37.8)$ & $2145(42.2)$ & \\
\hline $11 \mathrm{pm}-7 \mathrm{am}$ & $9507(28.2)$ & $2427(47.7)$ & \\
\hline
\end{tabular}

Table 2 Percentages of LWBS in patient groups

\begin{tabular}{lcccc}
\hline & $\mathbf{N}$ & $\mathbf{n}$ & Percentage of LWBS & $\mathbf{9 5 \%} \mathbf{C l}$ \\
\hline Sex & & & & \\
\hline Male & 20940 & 2634 & 12.58 & $(12.14,13.03)$ \\
\hline Female & 17838 & 2452 & 13.75 & $(13.25,14.26)$ \\
\hline
\end{tabular}

Age

\begin{tabular}{lcccc}
\hline$<14$ yrs & 11015 & 933 & 8.47 & $(7.95,8.99)$ \\
\hline $14-<20 y r s$ & 2119 & 311 & 14.67 & $(13.23,16.25)$ \\
\hline $20-<40 y r s$ & 10389 & 1791 & 17.24 & $(16.53,17.98)$ \\
\hline $40-<60 y r s$ & 8235 & 1205 & 14.63 & $(13.89,15.41)$ \\
\hline $60-<80 y r s$ & 6082 & 722 & 11.87 & $(11.08,12.71)$ \\
\hline 80yrs \& above & 939 & 125 & 13.3 & $(11.29,15.64)$
\end{tabular}

\section{Triage}

\begin{tabular}{lcccc}
\hline P1 \& P2 & 6942 & 90 & 1.3 & $(1.06,1.59)$ \\
\hline P3 & 27984 & 4409 & 15.76 & $(15.33,16.19)$ \\
\hline P4 & 3852 & 587 & 15.24 & $(14.14,16.41)$ \\
\hline
\end{tabular}

\section{Diversion Status}

\begin{tabular}{lllcr}
\hline Off Diversion & 26031 & 2558 & 9.83 & $(9.47,10.19)$ \\
\hline On Diversion & 12747 & 2528 & 19.83 & $(19.15,20.53)$ \\
\hline
\end{tabular}

\section{Months}

\begin{tabular}{lcccc}
\hline April & 3590 & 231 & 6.43 & $(5.68,7.28)$ \\
\hline May & 3976 & 319 & 8.02 & $(7.22,8.91)$ \\
\hline June & 3810 & 320 & 8.4 & $(7.56,9.32)$ \\
\hline July & 4091 & 370 & 9.04 & $(8.2,9.96)$ \\
\hline August & 4191 & 483 & 11.52 & $(10.59,12.53)$ \\
\hline September & 5002 & 916 & 18.31 & $(17.27,19.41)$ \\
\hline October & 5251 & 996 & 18.97 & $(17.93,20.05)$ \\
\hline November & 4706 & 786 & 16.7 & $(15.66,17.79)$ \\
\hline December & 4158 & 665 & 15.99 & $(14.91,17.14)$ \\
\hline Weekdays & & & & \\
\hline Saturday & 5704 & 644 & 11.29 & $(10.49,12.14)$ \\
\hline Sunday & 6160 & 955 & 15.5 & $(14.62,16.43)$ \\
\hline Monday & 5524 & 753 & 13.63 & $(12.75,14.56)$ \\
\hline Tuesday & 5350 & 693 & 12.95 & $(12.08,13.88)$ \\
\hline Wednesday & 5247 & 661 & 12.6 & $(11.73,13.52)$ \\
\hline Thursday & 5301 & 711 & 13.41 & $(12.52,14.36)$ \\
\hline Friday & 5492 & 669 & 12.18 & $(11.34,13.07)$ \\
\hline Waiting time & & & & \\
\hline
\end{tabular}

\section{Waiting time (Min)}

\begin{tabular}{lcccc}
\hline 0-30 min. & 24353 & 502 & 2.06 & $(1.89,2.25)$ \\
\hline 31-60 min. & 3097 & 597 & 19.28 & $(17.93,20.7)$ \\
\hline >61 min. & 11327 & 3987 & 35.20 & $(34.32,36.08)$ \\
\hline Shift & & & & \\
\hline 7am - 3pm & 11885 & 514 & 4.32 & $(3.97,4.71)$ \\
\hline 3pm - 11pm & 14891 & 2145 & 14.4 & $(13.85,14.98)$ \\
\hline $11 p m-7 a m$ & 12002 & 2427 & 20.22 & $(19.51,20.95)$ \\
\hline
\end{tabular}


Table 3 Patient characteristics of ED visits by Whether or not the patient left without being seen

\begin{tabular}{|c|c|c|c|c|}
\hline & LWBS -ve (\%) & LWBS +ve (\%) & Unadjusted OR (95\% Cl) & Adjusted OR (95\% Cl) \\
\hline \multicolumn{5}{|c|}{ Triage Category } \\
\hline $\mathrm{P} 1 \& \mathrm{P} 2$ & 20.34 & 1.77 & Ref. & Ref. \\
\hline P3 & 69.97 & 86.69 & $14.24(11.54-17.58)$ & $13.62(8.72-21.3)$ \\
\hline $\mathrm{P} 4$ & 9.69 & 11.54 & $13.69(10.93-17.15)$ & $13.14(8.04-21.49)$ \\
\hline \multicolumn{5}{|c|}{ Diversion Status } \\
\hline Off & 69.61 & 50.26 & Ref. & Ref. \\
\hline On & 30.39 & 49.74 & $2.26(2.13-2.42)$ & $1.49(1.26-1.76)$ \\
\hline \multicolumn{5}{|l|}{ Age category } \\
\hline Adult & 29.15 & 18.34 & Ref. & Ref. \\
\hline Pediatric & 70.85 & 81.66 & $0.55(0.49-0.61)$ & $0.57(0.48-0.66)$ \\
\hline \multicolumn{5}{|l|}{ Shifts of Day } \\
\hline $7 a m-3 p m$ & 34 & 10.1 & Ref. & Ref. \\
\hline $3 \mathrm{pm}-11 \mathrm{pm}$ & 37.8 & 42.2 & $3.75(3.39-4.15)$ & $3.47(2.83-4.26)$ \\
\hline $11 \mathrm{pm}-7 \mathrm{am}$ & 28.2 & 47.7 & $5.60(5.15-6.28)$ & $2.44(1.95-3.05)$ \\
\hline \multicolumn{5}{|l|}{ Months } \\
\hline April & 9.97 & 4.54 & Ref. & Ref. \\
\hline May & 10.86 & 6.27 & $1.26(1.06-1.51)$ & $0.92(0.66-1.29)$ \\
\hline June & 10.36 & 6.29 & $1.33(1.12-1.59)$ & $0.747(0.526-1.06)$ \\
\hline July & 11.05 & 7.27 & $1.44(1.22-1.72)$ & $0.73(0.52-1.04)$ \\
\hline August & 11.01 & 9.5 & $1.89(1.61-2.23)$ & $0.96(0.69-1.32)$ \\
\hline September & 12.13 & 18.01 & $3.26(2.80-3.79)$ & $1.79(1.34-2.4)$ \\
\hline October & 12.63 & 19.58 & $3.40(2.93-3.96)$ & $2.21(1.57-3.11)$ \\
\hline November & 11.63 & 15.45 & $2.92(2.50-3.40)$ & $1.42(1.04-1.94)$ \\
\hline December & 10.37 & 13.08 & $2.77(2.37-3.24)$ & $1.27(0.9-1.78)$ \\
\hline
\end{tabular}

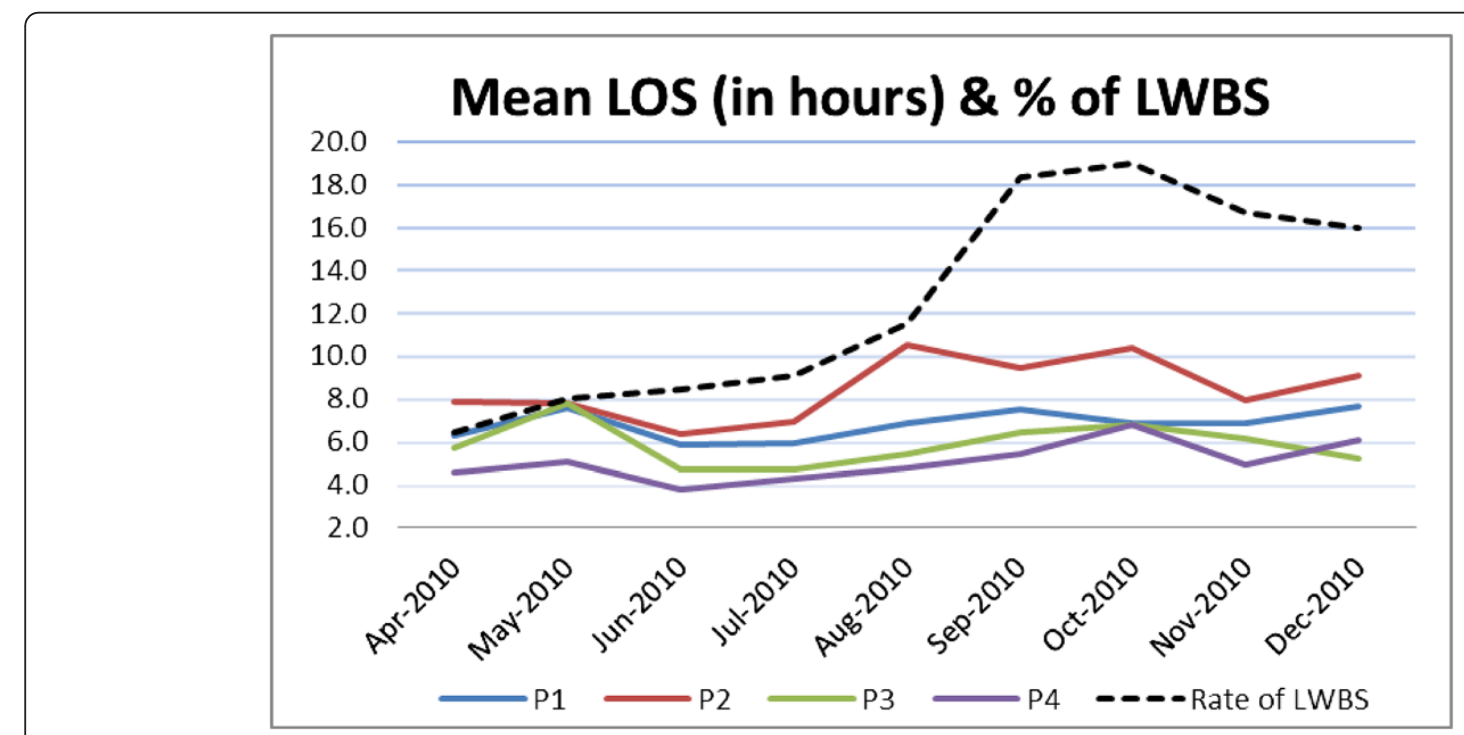

Figure 1 Relationship of length of stay, triage category and LWBS patients. 


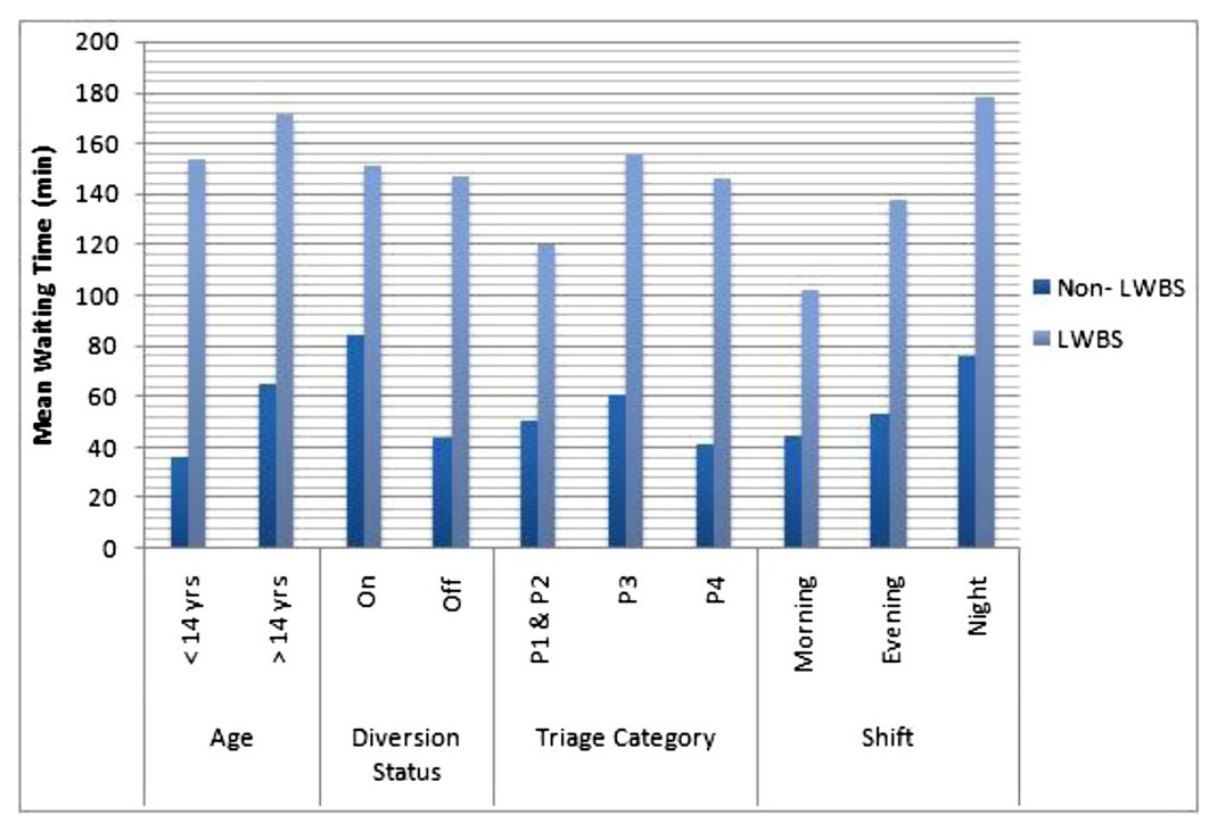

Figure 2 Relationship between Age, Diversion Status, shift of day and LWBS with respect to waiting time.

were of fever, non-specific complaints, abdominal pain, and vomiting/ diarrhea. Co-morbid was identified in $12.6 \%$ of patients with LWBS visits. Total patients who returned to hospital within 48 hours were 181 in LWBS group vs. 251 among the patients who were discharge; which means overall $3.6 \%$ of the LWBS patients vs. $1.11 \%$ of discharged patients needed to revisit in ED for medical care. Among the LWBS, 77 (1.5\%) and 6(0.26\%) in the discharge group required admission to the inpatient units (Table 4).

\section{Discussion}

To the best of our knowledge, this is the first study to describe the characteristics of Pakistani patients who left

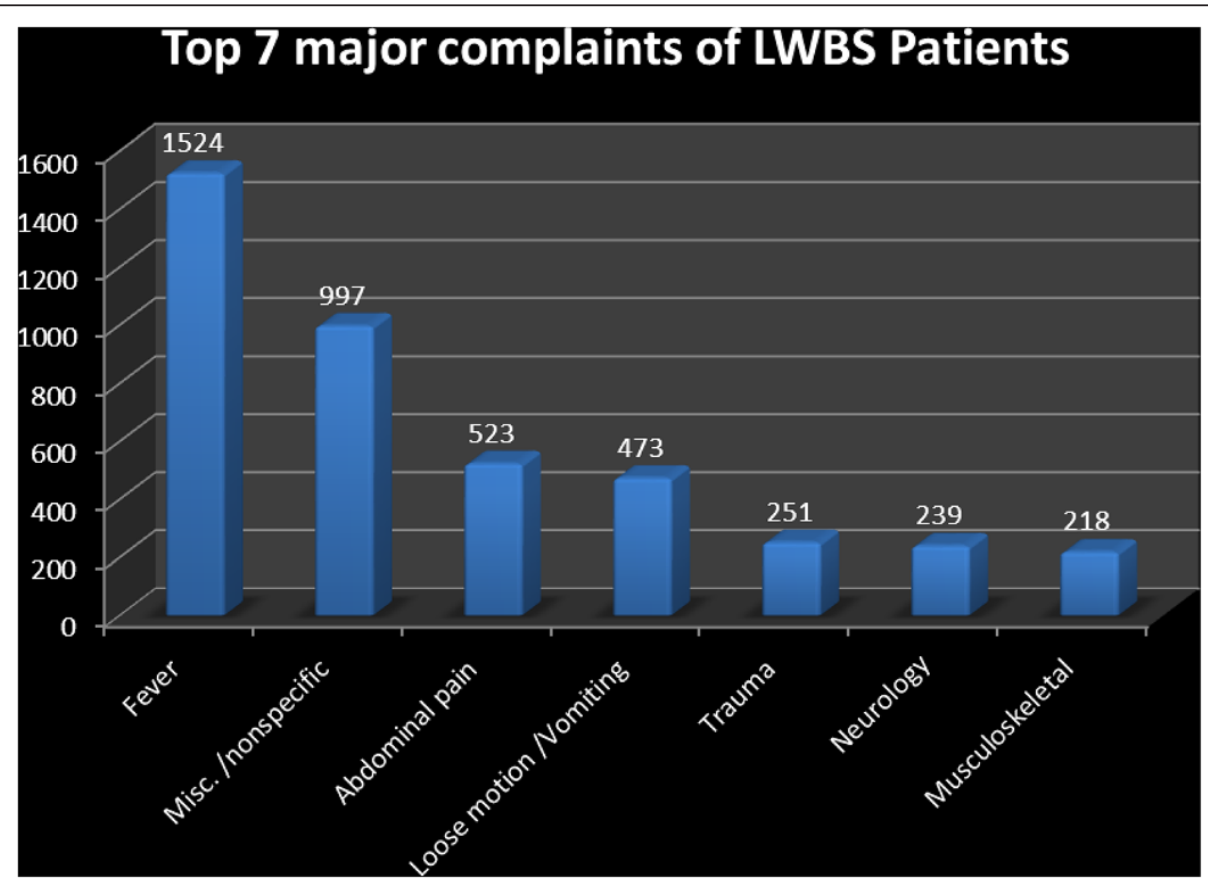

Figure 3 Top Seven Complaints of patients who left without being seen. 
Table 4 Characteristics of patients with return visits by months

\begin{tabular}{|c|c|c|c|c|c|c|c|}
\hline $\begin{array}{l}\text { Visit month } \\
\quad \text { year }\end{array}$ & Total patient & Left patient & $\begin{array}{l}\text { Rate of return } \\
\text { visits in LWBS n (\%) }\end{array}$ & $\begin{array}{l}\text { Rate of admission } \\
\text { in LWBS } n(\%)\end{array}$ & Discharge patients & $\begin{array}{c}\text { Rate of return } \\
\text { in } \mathrm{D} / \mathrm{C} \mathrm{n}(\%)\end{array}$ & $\begin{array}{l}\text { Rate of admission } \\
\text { in } \mathrm{D} / \mathrm{C} \mathrm{n}(\%)\end{array}$ \\
\hline Apr-2010 & 3356 & 231 & $8(3.6)$ & $1(0.4)$ & 2176 & $13(0.59)$ & $1(0.04)$ \\
\hline May-2010 & 3656 & 319 & $10(3.1)$ & $3(0.9)$ & 2335 & $14(0.6)$ & 0 \\
\hline Jun-2010 & 3489 & 320 & $16(5.0)$ & $4(1.3)$ & 2322 & $15(0.64)$ & $1(0.04)$ \\
\hline Jul-2010 & 3720 & 370 & $11(3.0)$ & $3(0.8)$ & 2556 & $23(0.9)$ & 0 \\
\hline Aug-2010 & 3707 & 483 & $17(3.5)$ & $6(1.2)$ & 2379 & $35(1.47)$ & 0 \\
\hline Sep-2010 & 4085 & 916 & $48(5.3)$ & $20(2.2)$ & 2979 & $45(1.51)$ & $1(0.03)$ \\
\hline Oct-2010 & 4253 & 996 & $36(3.6)$ & $15(1.5)$ & 2933 & $43(1.46)$ & $3(0.10)$ \\
\hline Nov-2010 & 3918 & 786 & $19(2.4)$ & $8(1.0)$ & 2732 & $42(1.53)$ & 0 \\
\hline Dec-2010 & 3492 & 665 & $17(2.6)$ & $12(1.8)$ & 2188 & $21(0.96)$ & 0 \\
\hline Total & 33676 & 5086 & $181(3.6)$ & $77(1.5)$ & 2260 & $251(1.11)$ & $6(0.26)$ \\
\hline
\end{tabular}

emergency department without being seen by a physician from a tertiary care hospital. We have described the relationship of LWBS with age, triage category, day of week, and shift of day, diversion status and waiting time. We found that in this study LWBS were 13\% which is comparable to other international data $(1.0-15 \%)$ but higher than the benchmark set by USA $(1.7 \%)[16,17,33]$.

Although the sex of those who LWBS does not have significant effect in a multiple regression model, it appears that age of a patient had a profound impact (Table 3). The odds of leaving for male patient who is 20-40 years of age is 17 times more than a patient at extremes of age, regardless of severity of illness. Children were found to be at a lower risk of being left, this may show increased sensitivity and nonspecific sign and symptoms towards extremes of age that gives them priority over other age groups [15,23,34]. Proportion of LWBS are higher in females contrary to international data may be because in our community structure females have the responsibility of taking care of all the household things as well their health is not given as much priority because of existing inequities in our communities $[35,36]$.

It was observed that higher proportions of low acuity (98.2\%) patients with less severe illnesses like fever, upper respiratory tract infection (URTI), acute gastroenteritis were leaving. Research has shown that LWBS and acuity has a dose- response relationship; with $15.2 \%$ of non-urgent patients leaving as compared to $0.1 \%$ of critical patients $[10,13,37]$. The fact that most of those patients who left although had low acuity illnesses yet they required some work up or treatment e.g. abdominal pain or diarrhea with dehydration, highlights the importance of accessibility of urgent care settings or short stay units. This could be assessed by the percentage of subsequent return visit in the ED after leaving. The return visits in our study are found to be $3.6 \%$ much higher than the internationally reported numbers $(1.2 \%)$ in a USA study with $1.5 \%$ requiring hospital admission subsequently [38].
A high number of walk-in patients such as those with fever or URTI utilize the ED mostly in after hours, and usually spend a long time in waiting because of their relatively stable condition. This fact also emphasizes the need for creating structures such as fast track Clinics or urgent care centers that cater the high influx of patients with seasonal illnesses who need not be referred to a tertiary care hospital for treatment and a separate patient care area for elderly patients [39-42].

From the results, it appears that patients who are asked to wait for a longer time period are also more likely to leave than those who are assigned bed within a relatively shorter time span. The odds for leaving in this study are $0.2 \%$ with every 10 minutes increase in waiting time. Although the accuracy of waiting time duration is uncertain, percentages have been described in other studies [17,22,27,29,37,43-45]. Probable reasons could be either patients got tired of waiting, seek advice in another healthcare facility or they felt better and left $[15,20,46,47]$.

The contributory factors for LWBS are overcrowding due to high patient influx and boarded patients in ED, lack of awareness among general population regarding ED utilization as well as inefficient primary health care facilities $[20,39,48-52]$. This crowding result into prolong waiting hours and ultimately increased rate of LWBS. In our institution because of lack of availability of inpatient beds in high acuity areas these patients who are either critically ill or intubated have to stay in the ED at times for more than 24-48 hours before their final disposition. The situation further worsen when more and more critical patients continue to land in the emergency department with limited resources like nursing staff and beds available. It is a proven phenomenon that when ED was crowded and on diversion there was 2.26 times risk of leaving the ED. Similar results have been reported by TL Viet and K $\mathrm{V}$ Rhodes that ED crowding increases the LWBS rate [21]. Increased percentages of LWBS during weekend or night shift and seasonal variations gives insight into 
epidemics such as dengue fever, inadequate outpatient services on the weekends and after hour's utilization of ED services for minor illnesses [16,21,51,53-56]. Our data had demonstrated a sudden increase in LWBS patients in the third quarter that coincide with the dengue epidemic of 2010 in Pakistan [57,58]. A strong seasonal variation with highest LWBS (up to 70\%) in winters is also found in other studies [45].

There are certain limitations of this study. First data were collected retrospectively. Secondly the study was conducted in a single tertiary care private hospital therefore results may not be generalized. Our department is the first in Pakistan to practice a defined triage system which started recently. Very little is known about the reliability and validity of the triage at our institute. This is the first ever analyzed data from AKUH-ED. Follow up studies are needed to address this issue in detail.

The cross sectional design of study did not enable us to follow the clinical outcome of LWBS patients in detail. Additional studies are required to determine subsequent morbidity and mortality as well as other hospital factors affecting the percentage of LWBS. As all the patients are not the registered patients at AKUH, so the return visit of all the patients who had been triaged cannot be traced for any adverse outcome. This was the first reported data so we haven't studied the different age group characteristics separately. Subsequent studies on pediatric, adult and geriatric patients are needed to further elaborate their characteristics and factors affecting their decision of leaving.

\section{Conclusions}

In this study, we found certain factors were strongly associated with LWBS such as age, low triage acuity, weekend, and night shift presentation and prolonged waiting times. ED Diversion was also associated with higher odd of leaving. This is only a single center data from a private tertiary care hospital and figures could be different in other public or private settings.

Strategies should be designed to shorten the waiting time and additional outpatient facilities such as fast track clinics to reduce the burden of these patients from ED and avoid possible bad outcome in this population who miss the opportunity of health care provision due to weak primary care facilities.

\section{Additional files}

Additional file 1: Patient Flow in ED through Triage Desk: It describes the flow of patients in the emergency department of AKUH at AKUH -ED.

Additional file 2: Triage Categorization.

Additional file 3: Electronic Record Management System functionality.

\section{Abbreviations}

ED: Emergency Department; LWBS: Left without Being Seen; OR: Odd Ratio; Cl: Confidence Interval; AKUH: Aga Khan University Hospital; P1: Priority Level 1; P2: Priority Level 2; P3: Priority Level 3; P4: Priority Level 4; URTI: Upper Respiratory Tract Infection; HTN: Hypertension.

\section{Competing interests}

The authors declare that they have no competing interests.

\section{Authors' contributions}

JF and MK contributed equally to the work. MUM participated in the design and data analysis. JF and MK made the draft. AM reviewed the manuscript and gave the final approval. All authors read and approved the final manuscript.

\section{Acknowledgements}

I would like to thank Shehzad merchant from information technology department and Dr. Ahsan Jamil Department manager. Both helped in retrieving data from the ERMS system. Asher helped us in answering the reviewers comment as a Biostatics person. We would like to show our gratitude to all referees, their valuable comments have helped us in improving the quality of our study.

Received: 17 October 2011 Accepted: 23 September 2012 Published: 16 January 2013

\section{References}

1. McPheeters RA: Counter-point: frequent users of the emergency department: meeting society's needs. West J Emergen Med 2009, 10(3):195.

2. Derlet RW, Richards JR, Kravitz RL: Frequent overcrowding in US emergency departments. Acad Emerg Med 2001, 8(2):151-155.

3. Rowe BH, Channan P, Bullard M, Blitz S, Saunders LD, Rosychuk RJ, Lari H, Craig WR, Holroyd BR: Characteristics of patients who leave emergency departments without being seen. Acad Emerg Med 2006, 13(8):848-852.

4. McCarthy ML, Zeger SL, Ding R, Levin SR, Desmond JS, Lee J, Aronsky D: Crowding delays treatment and lengthens emergency department length of stay, even among high-acuity patients. Ann Emerg Med 2009, 54(4):492-503. e494.

5. Trzeciak S, Rivers E: Emergency department overcrowding in the united states: an emerging threat to patient safety and public health. Emerg Med J 2003, 20(5):402.

6. Hoot NR, Aronsky D: Systematic review of emergency department crowding: causes, effects, and solutions. Ann Emerg Med 2008, 52(2):126-136. e121.

7. Weiss SJ, Ernst AA, Derlet R, King R, Bair A, Nick TG: Relationship between the national ED overcrowding scale and the number of patients who leave without being seen in an academic ED. Am J Emerg Med 2005, 23(3):288-294.

8. Polevoi SK, Quinn JV, Kramer NR: Factors associated with patients who leave without being seen. Acad Emerg Med 2005, 12(3):232-236.

9. Pines JM: The left without being seen rate: an imperfect measure of emergency department crowding. Acad Emerg Med 2006, 13(7):807-807.

10. Ding R, McCarthy ML, Li G, Kirsch TD, Jung JJ, Kelen GD: Patients who leave without being seen: their characteristics and history of emergency department use. Ann Emerg Med 2006, 48(6):686-693.

11. Arendt KW, Sadosty AT, Weaver AL, Brent CR, Boie ET: The left-withoutbeing-seen patients* 1: what would keep them from leaving? Ann Emerg Med 2003, 42(3):317-323.

12. Kelen GD, Scheulen JJ, Hill PM: Effect of an emergency department (ED) managed acute care unit on ED overcrowding and emergency medical services diversion. Acad Emerg Med 2001, 8(11):1095-1100.

13. Mohsin M, Young L, leraci S, Bauman AE: Factors associated with walkout of patients from New south Wales hospital emergency departments, Australia. Emerg Med Australas 2005, 17(5 6):434-442.

14. Hsia RY, Asch SM, Weiss RE, Zingmond D, Liang LJ, Han W, McCreath H, Sun $B C$ : Hospital determinants of emergency department left without being seen rates. Ann Emerg Med 2011, 58(1):24-32. e3.

15. Baker DW, Stevens CD, Brook RH: Patients who leave a public hospital emergency department without being seen by a physician. JAMA 1991, 266(8):1085 
16. Sainsbury SJ: Emergency patients who leave without being seen: are urgently ill or injured patients leaving without care? Mil Med 1990, 155(10):460-464.

17. Pham JC, Ho GK, Hill PM, McCarthy ML, Pronovost PJ: National study of patient, visit, and hospital characteristics associated with leaving an emergency department without being seen: predicting LWBS. Acad Emerg Med 2009, 16(10):949-955.

18. Bernstein SL, Aronsky D, Duseja R, Epstein S, Handel D, Hwang U, McCarthy M, John McConnell K, Pines JM, Rathlev N: The effect of emergency department crowding on clinically oriented outcomes. Acad Emerg Med 2008, 16(1):1-10.

19. Guttmann A, Schull MJ, Vermeulen MJ, Stukel TA: Association between waiting times and short term mortality and hospital admission after departure from emergency department: population based cohort study from Ontario, Canada. Brit Med J 2011, 342:D2983.

20. Liao HC, Liaw SJ, Hu PM, Lee KT, Chen CM, Wang FL: Emergency department patients who leave without being seen by a doctor: the experience of a medical center in northern Taiwan. Chang Gung Med J 2002, 25(6):367-373.

21. Vieth $T L$, Rhodes KV: The effect of crowding on access and quality in an academic ED. Am J Emerg Med 2006, 24(7):787-794.

22. Goodacre S, Webster A: Who waits longest in the emergency department and who leaves without being seen? Emerg Med J 2005, 22(2):93.

23. Kennedy M, MacBean CE, Brand C, Sundararajan V, Mc DTD: Review article: leaving the emergency department without being seen. Emerg Med Australas 2008, 20(4):306-313.

24. Johnson M, Myers S, Wineholt J, Pollack M, Kusmiesz AL: Patients who leave the emergency department without being seen. J Emerg Nurs 2009, 35(2):105-108.

25. Burt CW, McCaig LF: Staffing, capacity, and ambulance diversion in emergency departments: United States, 2003-04. Adv Data 2006, 376 (376):1-24.

26. Kronfol RN, Childers K, Caviness AC: Patients who leave our emergency department without being seen: the Texas Children's hospital experience. Pediatr Emerg Care 2006, 22(8):550.

27. Baibergenova A, Leeb K, Jokovic A, Gushue S: Missed opportunity: patients who leave emergency departments without being seen. Healthc Policy 2006, 1(4):35-42

28. Hobbs D, Kunzman SC, Tandberg D, Sklar D: Hospital factors associated with emergency center patients leaving without being seen. Am J Emerg Med 2000, 18(7):767-772.

29. Fernandes CM, Price A, Christenson JM: Does reduced length of stay decrease the number of emergency department patients who leave without seeing a physician? J Emerg Med 1997, 15(3):397-399.

30. Mehdi IJ: Emergency medicine in Pakistan. Ann Emerg Med 1996, 27(1):84-88.

31. Razzak JA, Ahmed A, Saleem AF, Nasrullah M: Perceived need for emergency medicine training in Pakistan: a survey of medical education leadership. Emerg Med Australas 2009, 21(2):143-146.

32. Arnold $J$ : International emergency medicine and the recent development of emergency medicine worldwide. Ann Emerg Med 1999, 33(1):97-103.

33. Derlet RW, Richards JR: Overcrowding in the nation's emergency departments: complex causes and disturbing effects. Ann Emerg Med 2000, 35(1):63-68.

34. Bourgeois FT, Shannon MW, Stack AM: "Left without being seen": a national profile of children Who leave the emergency department before evaluation. Ann Emerg Med 2008, 52(6):599-605.

35. Dijkstra AG, Hanmer LC: Measuring socio-economic gender inequality: toward an alternative to the UNDP gender-related development index. Fem Econ 2000, 6(2):41-75.

36. Mumtaz Z, Salway S, Waseem M, Umer N: Gender-based barriers to primary health care provision in Pakistan: the experience of female providers. Health Policy Plann 2003, 18:261-269.

37. Chan TC, Killeen JP, Kelly D, Guss DA: Impact of rapid entry and accelerated care at triage on reducing emergency department patient wait times, lengths of stay, and rate of left without being seen. Ann Emerg Med 2005, 46(6):491-497.

38. Kurowski EM, Byczkowski T, Timm N: Return visit characteristics among patients who leave without being seen from a pediatric ED. Am J Emerg Med 2012, 30(7):1019-1024.
39. Ionescu-Ittu R, McCusker J, Ciampi A, Vadeboncoeur AM, Roberge D, Larouche D, Verdon J, Pineault R: Continuity of primary care and emergency department utilization among elderly people. Can Med Assoc J 2007, 177(11):1362

40. Baumann MR, Strout TD: Triage of geriatric patients in the emergency department: validity and survival with the emergency severity index. Ann Emerg Med 2007, 49(2):234-240.

41. Devkaran S, Parsons H, Van Dyke M, Drennan J, Rajah J: The impact of a fast track area on quality and effectiveness outcomes: a middle eastern emergency department perspective. BMC Emerg Med 2009, 9:11.

42. Darrab AA, Fan J, Fernandes C, Zimmerman R, Smith R, Worster A, Smith T, O'Connor K: How does fast track affect quality of care in the emergency department? Eur J Emerg Med 2006, 13(1):32.

43. Monzon J, Friedman SM, Clarke C, Arenovich T: Patients who leave the emergency department without being seen by a physician: a controlmatched study. CJEM 2005, 7(2):107-113.

44. Green RA, Wyer PC, Giglio J: ED walkout rate correlated with ED length of stay but not with ED volume or hospital census. Acad Emerg Med 2002, 9(5):514.

45. Lee G, Endacott R, Flett K, Bushnell R: Characteristics of patients who did not wait for treatment in the emergency department: a follow up survey. Accid Emerg Nurs 2006, 14(1):56-62.

46. Richardson DB, Bryant M: Confirmation of association between overcrowding and adverse events in patients who do not wait to be seen. Acad Emerg Med 2004, 11(5):462.

47. Lee K, Wong T, Chan R, Lau C: A study of patients who leave without notice in an A \& E department. Accid Emerg Nurs 1998, 6(2):118-121.

48. Clarey AJ, Cooke MW: Patients who leave emergency departments without being seen: literature review and English data analysis. Emerg Med J 2011, 29(8):617-621.

49. Lang T, Davido A, Diakité B, Agay E, Viel JF, Flicoteaux B: Using the hospital emergency department as a regular source of care. Eur J Epidemiol 1997, 13(2):223-228

50. Carret M, Fassa A, Kawachi I: Demand for emergency health service: factors associated with inappropriate use. BMC Health Serv Res 2007, 7(1):131.

51. Sempere-Selva T, Peiró $S$, Sendra-Pina P: Inappropriate use of an accident and emergency department: magnitude, associated factors, and reasons-an approach with explicit criteria. Ann Emerg Med 2001, 37(6):568-579.

52. Moineddin RMC, Agha M, Zagorski B, Glazier R: Modeling factors influencing the demand for emergency department services in Ontario: a comparison of methods. BMC Emerg Med 2011, 11(13).

53. Qureshi JA, Notta NJ, Salahuddin N, Zaman V, Khan JA: An epidemic of dengue fever in Karachi-associated clinical manifestations. J Pak Med Assoc 1997, 47(7):178.

54. Ahmed S, Arif F, Yahya Y, Rehman A, Abbas K, Ashraf S, Akram DS: Dengue fever outbreak in Karachi 2006-a study of profile and outcome of children under 15 years of age. J Pak Med Assoc 2008, 58(1):4-8.

55. Khan E, Siddiqui J, Shakoor S, Mehraj V, Jamil B, Hasan R: Dengue outbreak in Karachi, Pakistan, 2006: experience at a tertiary care center. Trans $R$ Soc Trop Med Hyg 2007, 101(11):1114-1119.

56. Ahsan T: Dengue fever: a regular epidemic? Epidemiology 2005, 2:1.

57. Jahan F: Dengue Fever (DF) in Pakistan. Asia Pac Fam Med 2011, 10(1):1.

58. Mahboob A, lqbal Z, Javed R, Taj A, Munir A, Akhtar SM: Clinical characteristics of the patients with Dengue fever: Report of 48 patients in 2010. J Ayub Med Coll Abbottabad 2010, 22(4):120-123.

doi:10.1186/1471-227X-13-1

Cite this article as: Fayyaz et al:: Missing the boat: odds for the patients who leave ED without being seen. BMC Emergency Medicine 2013 13:1. 